\title{
Autoridad, poder y razón de Estado en el teatro de Antonio Enríquez Gómez*
}

\section{Authority, Power and Reason of State in the Theater of Antonio Enríquez Gómez}

\author{
Manuel Calderón Calderón \\ Universidade de Lisboa \\ mcc2003@gmail.com \\ ORCID iD: http://orcid.org/0000-0002-9414-5985
}

\section{RESUMEN}

Las comedias de contenido político de Antonio Enríquez Gómez reflejan, a través de sus cuatro temas recurrentes (la dicotomía ley-poder, la razón de Estado, la aplicación de la ley desde el punto de vista político y el perdón), las líneas maestras del naciente Leviatán o Estado moderno. Aunque la relación patriarcal entre el Rey y sus súbditos está anclada en presupuestos iusnaturalistas, el amor debe supeditarse a la eficacia en el ejercicio del poder. Y si unas veces los personajes dudan entre el racionalismo aristotélico-tomista y la razón de Estado maquiavélico-hobbesiana, en otras ocasiones oponen la fuerza, el riesgo y la voluntad del «pueblo» a la «razón» divina de la ley. En el contexto de la crisis de la Monarquía Hispánica, las críticas de Enríquez Gómez no se limitan a los representantes y funcionarios del Estado, sino que abarcan a la Iglesia y al Tercer Estado.

Palabras Clave: Antonio Enríquez Gómez; Fernando de Zárate; teatro español del siglo XVII; relaciones literarias hispano-portuguesas.

\begin{abstract}
Comedies of political content written by Antonio Enríquez Gómez reflect, through the analysis of its four recurring themes - the dichotomy between law and power, the reason of state, the law enforcement from a political point of view and forgiveness-- the outlines of the nascent Leviathan or modern state. Although the patriarchal relationship between the Monarch and his people is based on a iusnaturalist conception, love should be subject to the effectiveness in the exercise of power. The characters in this theatre sometimes hesitate between Aristotelian-Thom-
\end{abstract}

* En el marco del proyecto de investigación «Teatro Português do Século XVII: uma biblioteca digital» (PTDC/CLE-LLI/122193/2010). 
istic rationalism and Machiavellian-Hobbesian reason of state and, on other occasions, they oppose the people's strength, risk and will to the divine reason of Law. In the context of the Hispanic Monarchy crisis, Enríquez Gómez's critics are not limited to Government representatives and civil servants, but also include the Church and common people (Third State).

Key words: Antonio Enríquez Gómez; Fernando de Zárate; $17^{\text {th }}$ Century Hispanic Theatre; Spanish-Portuguese Literary Relationships.

A lo largo del seiscientos, la crisis de las autoridades en materia política es resultado de la tensión surgida el siglo anterior entre el deber ser de la utopía (Moro) y lo que es de la razón de Estado (Maquiavelo). En un siglo de desengaños, parafraseando a Góngora, la erudición de los antiguos también engaña. Tanto en la teoría del teatro (el Arte nuevo) como de la política, hubo un reajuste de los modelos y de la propia noción de autoridad, cada vez más asentada en el gusto estético y la opinión política de un vulgo hastiado de las inacabables guerras teológicas y de religión. «En las acciones de todos los hombres, especialmente de los príncipes, donde no hay tribunal al que apelar - constata Maquiavelo-, se atiende a los resultados [...], ya que el vulgo se deja cautivar por la apariencia y el éxito, y en el mundo no hay más que vulgo» (Maquiavelo, 1991: 73). Idea que confirma Baltasar Gracián cuando advierte que «ninguno conseguirá jamás el crédito de consumado en cualquier empleo sin el realce de un plausible gusto». Tanto el Rey como el Orador, el Historiador o el Filósofo «atiendan todos al gusto ajeno universal, que es la norma del elegir» (Gracián, 1993: 130).

Producto típico de aquel siglo de incertidumbres angustiosas es el conquense de familia judeoconversa Antonio Enríquez Gómez, un escritor autodidacta, hijo y nieto de judeoconversos condenados por la Inquisición, que anduvo azacaneándose por Sevilla, Madrid, Burdeos y Ruan, dividiendo su fidelidad política (Luis XIV, João IV) y religiosa (marranismo), trasterrado o bien ocultando su personalidad (Fernando de Zárate), buscando refugio entre sus parientes y otras veces huyendo ellos'.

${ }^{1}$ Como los reyes pueden ser «eminentes en sus elecciones, así de empresas como de ministros», «elígense también los familiares, que son ayudantes del vivir, y las más veces enemigos no excusados» (Gracián, 1993: 132), pues cuando Fernando de Zárate fue arrestado el 21 de septiembre de 1661 por la Inquisición de Sevilla, «le poète essaie d'abord de défendre sa fausse identité devant le grand alguazil, mais son demi-frère et son cousin révèlent immédiatement que son véritable nom est Antonio Enríquez Gómez. Transféré le même jour dans un cachot du Saint-Office, l'écrivain abandonna son déguisement, désormais inutile», y tampoco logró «justifier deux perfides constatations faites par son cousin germain Francisco Luis» (Révah, 2003: 389-392). 
Aunque en sus tratados políticos no pasa de exponer unas ideas convencionales y en curso de desaparición ${ }^{2}$, Enríquez Gómez deja entrever, en su teatro, las líneas maestras del nuevo Leviatán que estaba configurándose. Analizando el sentido que adquieren en él los conceptos de ley, poder y razón de Estado, así como las ideas sobre el ejercicio del Gobierno, vemos asomar una crisis que es doblemente cultural y política, la cual necesita ser enmarcada en el contexto ideológico y filosófico del seiscientos.

\section{LEY Y PODER}

Las comedias de contenido político de Antonio Enríquez Gómez giran en torno a cuatro temas fundamentales ${ }^{3}$ : la dicotomía ley-poder, la Razón de Estado, la aplicación de la ley en el Gobierno y los tribunales, y el Perdón. La ley es la piedra de toque y el fundamento (por tanto, anterior) de la paz, la libertad y la justicia 4 . Ahora bien, ni para Bodin ni para Hobbes la ley es, en sí misma, importante. Lo decisivo es el poder (potestas) de quien tiene la fuerza para hacerla cumplir: no la discusión, la negociación ni los eventuales contenidos de la ley (pongamos los tres del Estado moderno: la técnica, la economía, la burocracia), sino la voluntad de poder y el sujeto de la decisión ${ }^{5}$.

${ }^{2}$ En Luis dado a Dios y Ana, Samuel dado de Dios a Elcana y Ana (Enríquez, 1645) y la Política angélica (Enríquez, 1647), Enríquez Gómez opone el rey justo (que sabe amar, castigar y premiar), vicario de Dios y de quien recibe su derecho a gobernar, al tirano; y el Estado bien gobernado por unos ministros ejemplares, regidos por la justicia, la misericordia y la honradez, al Estado mal gobernado por unos ministros hipócritas, envidiosos, egoístas y aduladores.

${ }^{3}$ Considero aquí las siguientes obras de Enríquez Gómez: la Primera y Segunda partes de Fernán Méndez Pinto (1974); la Primera y Segunda partes de El Gran Cardenal de España (Enríquez, s. a.; El Gran Cardenal de España, Don Gil de Albornoz. Segunda Parte. [manuscrito] (BNE Mss. 15.152 y 16.544); A lo que obliga el honor (1642); El Rey más perfecto (1991; ed. original de 1661); Los dos filósofos de Grecia (1663); El maestro de Alejandro (1666) y Las tres coronaciones de Carlos V (1675). De otras dos (Engañar para reinar y No hay contra el honor poder) ya me ocupé en Calderón Calderón (2016).

${ }^{4}$ Aristóteles (1990: I, 9, 1366b; y en El maestro de Alejandro: «yo nunca puedo servir mal / si me ajusto a la ley», f. 194ra); Maquiavelo (2008: II, 2); Hobbes (2004: 117 y 131 y 2013: 9); Espinosa (1986: II, 2 y 2012: XVI, 4). Sin embargo, Montesquieu sostiene que «hay una razón primigenia» y «antes de que se hubieran dado leyes, había relaciones de justicia posibles» (1985: I, i, 1).

${ }^{5}$ Bodin (1590: I, x); Hobbes (2004: 235; auctoritas, non veritas facit legem, en la edición latina; en la española, «lo que constituye la ley no es esa juris prudentia o sabiduría de jueces subordinados, sino la razón de ese hombre artificial nuestro al que llamamos Estado») y Hobbes (2013: 10 y 21); Montesquieu: «en una monarquía, el que hace observar las leyes está por encima de ellas» (1985: I, iii, 3); así como Carl Schmitt (2009: I). Para Maquiavelo es la combinatoria de las fuerzas (virtus) en pugna lo determinante en política, 
En relación con el ejercicio de este poder hay un tipo dramático que aparece constantemente en las obras de Enríquez Gómez: el gobernante soberbio. Nembrot, Ludovico (Engañar para reinar), Sancho el Bravo (No hay contra honor poder) y el príncipe Federico, cuyo padre «perdió por altivo / el reino de Babilonia» (Los dos filósofos de Grecia, f. 118rb), son avatares del poder absoluto, que ordena y manda, opuesto al poder que convence a quienes tienen que obedecer ${ }^{6}$.

El tema de El Gran Cardenal de España, Don Gil de Albornoz es el contraste entre el ejercicio del poder (la auctoritas) por parte del rey de Castilla, Pedro el Cruel, y la veritas de su principal consejero, el arzobispo y luego cardenal Gil de Albornoz. Una verdad, en este caso, opuesta a la «lisonja o amorosa voluntad» del monarca por María de Padilla, cuya influencia perniciosa en los asuntos de Estado contrasta con la prudencia y la sindéresis del privado ${ }^{8}$.

Pero el Rey acaba enojado con las admoniciones del Cardenal y haciendo uso de su soberanía, opta por «las leyes del gusto» frente a la legitimidad jurídica; pide explicaciones a Don Gil de Albornoz por haber anulado el nombramiento de «una hechura que yo hice» y concluye la Primera Parte desterrándolo a él y a su hermano Don Juan de Albornoz.

En El rey más perfecto, son Fernando III y su padre, Alonso IX de León, quienes encarnan la ley divina y la ley humana, que «es el poder» (Enríquez, 1991: v. 172), respectivamente. Mientras aquel reclama el trono de Castilla por línea materna, este se niega a dárselo, por boca de Don Álvaro Núñez, aduciendo la norma legal que da prioridad al cónyuge en la línea sucesoria:

no la dicotomía religiosa del bien y del mal. Los hombres —afirma- incluso están dispuestos a renunciar a la libertad con tal de tener poder (2008: I, 16). Y para Espinosa (1977: IV, Proposición $\mathrm{xx}$ ) el sentido de bueno y malo es, respectivamente, el aumento y disminución de la potencia de actuar a fin de desarrollar nuestro ser (conatus); además, quien tiene el monopolio del dominio normativo sobre lo bueno y lo malo, la justicia y la injusticia, es la autoridad política (Espinosa, 2012: Prefacio, 3 y XVI, 5).

${ }^{6}$ Distinción entre monarquía absoluta y monarquía constitucional que hará, en el siglo XIX, Camillo Benso, conde de Cavour (Schmitt, 2008: 19).

7 Enríquez Gómez, Antonio (s. a.). El Gran Cardenal de España, Don Gil de Albornoz [Primera Parte]. S. 1.: s. n. (BNE R/33890) y El Gran Cardenal de España, Don Gil de Albornoz. Segunda Parte. [manuscrito] (BNE Mss. 15.152 y 16.544).

8 «Mire vuestra Majestad / que debe usar del poder / de su grandeza» —exhorta María de Padilla al Rey. Pero el Arzobispo es «amigo / de la verdad; [...] / que adoro a Su Majestad, / pero temo sólo a Dios» (Jornada Primera). Y para el monarca tampoco «hay maldad / como no decir verdad /un hombre [...] / Quien verdad no dice al Rey / no es noble ni ha sido honrado» (Jornada Segunda). El conflicto entre la pasión del príncipe y los intereses o razón de Estado es un tema reiterado en la comedia del Siglo de Oro, que suele interpretarse desde el punto de vista moral. Aquí, en cambio, trato de situarlo en el marco de las ideas políticas. 
D. Álvaro Antes de jurar al rey tiene el Estado otra ley del mismo pueblo admitida.

Arzobispo Sin razón no hay ley alguna.

D. Álvaro Sí la tiene mi valor.

ArzoBisPo Ése mancilla mi honor.

D. Álvaro No hay honor si no hay fortuna (Enríquez, 1991: vv. 198-204).

De manera que frente a la razón divina de la ley ${ }^{9}$, Don Álvaro opone la fuerza (valor), el riesgo (fortuna) y la voluntad del pueblo ${ }^{10}$ o lo que es igual, un poder o soberanía ejercidos de forma activa ${ }^{11}$.

El protagonista de Fernán Méndez Pinto, natural del «gran reino de Sión, / a quien por nombre le dieron / Lusitania» (Enríquez, 1974: vv. 155-157) ${ }^{12}$, es precisamente un hombre de acción ${ }^{13}$, pues es sólo en la práctica del Derecho,

9 «Las ideas que tocan al trono de Dios» (1991: vv. 272-273), pues «los reyes por Dios gobiernan» (v. 304) — dice el Arzobispo cuando explica el simbolismo de la corona-. El marco ideológico es el iusnaturalismo clásico y escolástico; aunque para Espinosa «Dios no ejerce un reinado especial sobre los hombres, sino a través de quienes ejercen el Derecho del Estado» (2012: XIX, 1). Ante la pregunta del usurpador Rey de Dinamarca («iPuede uno lograr perdón reteniendo los frutos del delito?») él mismo se responde: no, según la Verdad, que está de tejas arriba, o «sí», según la Justicia, que está de tejas abajo y es fruto de un consenso alterable (Shakespeare, 1991c: 259); postulado del que parte también el capellán y guardasellos del cardenal de Winchester, Stogumber, en Santa Juana, esc. IV, de Bernard Shaw (1979).

${ }^{10}$ Como Worcester y sus aliados (uno de los cuales añade: «en el matorral del peligro cogeremos la flor de la seguridad») se disponen a «conducir nuestra fortuna con nuestros propios fuertes brazos» (Shakespeare, 1991a: 459 y 464). «Los monarcas han inventado el recurso de hacer creer que la majestad regia es sagrada y hace las veces de Dios en la Tierra, que tiene su origen en Dios y no en los votos y el acuerdo entre los hombres» (Espinosa, 2012: XVII, 1). «La equidad y la razón son leyes divinas y eternas» — dice el Jurista de Hobbes; pero «las leyes humanas no pueden arrancar las raíces de las malas acciones, que se encuentran en el corazón» (Hobbes, 2013: 7-8). Idea que reitera Espinosa, citando a Tácito; por eso, «las causas y los fundamentos naturales del Estado no habrá que extraerlos de las enseñanzas de la razón, sino de la naturaleza o condición común de los hombres» (1986: I, 2 y 7).

11 «Dada una cosa cualquiera, se da otra más potente por la que aquella puede ser destruida» (Espinosa, 1977: IV, Axioma). Lo que es glosado así por Gabriel Albiac: «la permanente posibilidad, el riesgo continuo de la aniquilación gravitan sobre el esencial conatus de permanencia, propio de todos los entes: no hay vida sin riesgo; ser es apuesta» (2013: 484).

12 «Era un lugar común en la polemística prorrestauracionista referirse a Jerusalén como prefiguración de Lusitania, es decir, Portugal» (Calderón Calderón, 2016: nota 27).

13 Aunque «cuerdo y prudente» (1974: vv. 172-174) o en palabras de Gracián, «diligente e inteligente» al mismo tiempo (1993: 168). Al comienzo de la comedia cuenta al Rey de la China la «peregrina historia» de sus últimos catorce años: a los veinte se enroló en la vuelta de Asia; llegó a Diu, estrecho de Meca y costas del Preste Juan; desde Malaca, don- 
de la justicia y la caridad donde se revela la razón, a la cual el Arzobispo Rodrigo de Mendoza apela en la comedia anterior (Jeremías 9, 23) ${ }^{14}$.

Al igual que El rey más perfecto, Los dos filósofos de Grecia tienen que dirimir una «grave materia de Estado»: qué príncipe extranjero (Andrónico o Lisipo) merece apoderarse del imperio de Lusidoro. Demócrito les propone que cada uno demuestre con hechos sus dotes políticas y militares. En cambio, Heráclito no se considera apto para juzgar y prefiere no involucrarse con la política, pues esta se basa en la mentira ${ }^{15}$. «Yo no juzgo, sino ejecuto la ley» —replica Demócrito, quien reconoce que incluso los «endiosados senadores» son mortales y que «en el solio sagrado, / una comedia los dioses / milagrosa compusieron $»^{16}$. Mas por eso mismo-añade en la segunda jornada- debemos interpretarla hasta el final lo mejor que podamos:

\begin{tabular}{cl} 
HerÁclito & \multicolumn{1}{c}{ ¿A qué paraíso eterno } \\
& viene el que nace? ¿No viene \\
& al calabozo tremendo \\
& deste mundo a padecer? \\
& ¿No le aguardan los tormentos \\
& de todo un libre albedrío? \\
& {$[\ldots]$} \\
Demócrito & Al que nace a navegar \\
& por piélagos tan inmensos
\end{tabular}

de embarcó el capitán Pedro de Faria, pasaron a Araun, en Sumatra, «puerto de cosarios»; naufragaron ante la playa de Pantanay, en la costa occidental de la península malaya, cuyos ríos estaban llenos de monstruos carnívoros, y sólo sobrevivieron él y su criado Duarte Pinto, peregrinos en la isla de Can durante diez días hasta su arribada a Arcadia [?], donde perdió al criado.

${ }^{14}$ Aristóteles distingue entre las virtudes éticas, que forman el carácter y nos hacen capaces de acciones nobles (1981: 1099b) y las virtudes dianoéticas, sociales o ciudadanas (1999: VII, 13, 9-10), inferiores a aquellas porque las primeras se adquieren por costumbre, hábito e imitación y las segundas sólo se aprenden: «por elegir lo que es bueno o malo tenemos cierto carácter, pero no por opinar» (1981: 1103a y 1112a). En el mismo sentido se expresa Espinosa (2012: XIV, 2); quien, en lugar de una teoría del conocimiento, redacta una Ética que no es más que la«descripción de la potencia autónoma, de sus conflictos ante otras potencias, de sus dominaciones y sus sometimientos, sus ilusorias esperanzas y sus mortales miedos» (Albiac, 2013: 417-418).

15 «Ciencia se llama el mentir»; además, todo es vanidad, «la vida es sueño» y el mundo es un «laberinto» 1leno de «desengaños» (Enríquez, 1663: f. 122ra). En la segunda jornada, llama a su colega «tahúr de Estado» (1663: f. 129 vb).

${ }^{16}$ Como advirtiera Micilo: «aquellos grandes colosos, obras de Fidias, Mirón o Praxíteles también son externamente un Posidón o un Zeus de gran belleza [...]; mas si te inclinas y observas el interior, verás barras, traviesas y clavos [...]; excuso mencionarte la multitud de ratas y musarañas que hacen de ellos su ciudad en ocasiones». Asimismo, los poderosos «cuando caen se asemejan extraordinariamente a los actores trágicos que dan un paso en falso y caen en medio de la escena» (Luciano, 1981: 385 y 387). 
le hacemos fiestas y damos

parabienes imperfectos.

En efecto, Demócrito ríe porque

con la antorcha racional tendida

voy alumbrando el orbe de la vida

y supuesto que alumbro con la mente

el penúltimo rayo del Oriente,

[...] yo soy quien te doy los buenos días (Enríquez, 1663: 116r).

Lo que está en juego no es tanto «la supresión de las tinieblas por la luz de la adequatio rei et intellectus» como la superación del miedo y la esperanza (es decir, la sumisión) para no depender más que de nosotros mismos, pues en eso consiste la libertad frente al libre arbitrio ${ }^{17}$.

Al final, Lisipo es quien regresa vivo de la guerra, se hace con el poder y destierra a los filósofos; pero Demócrito — alter ego del autor- proclama: «yo, peregrino en mi patria, / fui político en las otras [...], / porque piden mis palabras / ejecución en las obras»».

El Infante don Fernando también conoce la diferencia entre la ley y el imperio de la ley («el gobierno de la pluma / con la espada se defienda») en Las tres coronaciones de Carlos $V$. Y remedando al Arzobispo de Toledo, en El rey más perfecto, el Arzobispo de Numancia distingue allí entre legitimidad jurídica (la justicia asociada al Estado) y religiosa (la fe ligada a la Iglesia) cuando interpreta el simbolismo de la corona ${ }^{18}$ :

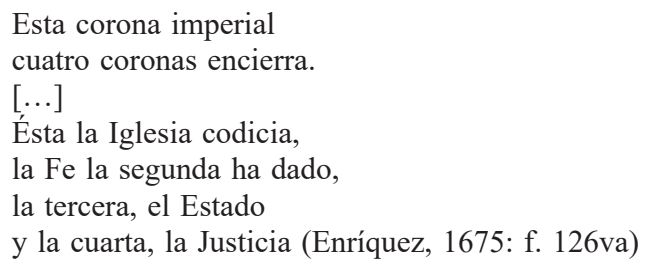

Repárese en que «el rey más perfecto» condena la doctrina albigense y manda ejecutar a los herejes no por razones religiosas, sino políticas, como explica el propio Enríquez Gómez en el diálogo segundo de su Política angé-

${ }^{17}$ La libertad es una «determinación del ser en general y no una propiedad del hombre [libre albedrío], siendo así que el hombre es sólo en la medida en que accede a la libertad» (Albiac, 2013: 422-423 y 448).

${ }^{18}$ Para Espinosa el Estado no debe legislar sobre cuestiones teóricas ni perseguir la expresión de las ideas (2012: Prefacio, 1); de manera que no hay que perseguir a los que disienten en la doctrina de la fe si en sus obras son respetuosos con el Derecho y no alteran las normas del Estado. Inversamente, «nadie puede ser obligado por la fuerza o por las leyes a ser feliz» (2012: XIV, 3 y VII, 4). 
lica (1647), donde sostiene que es legítimo que un príncipe cristiano acuda en defensa de otro no cristiano que haya sido injustamente agredido por un príncipe cristiano ${ }^{19}$. Y añade: «todo lo relacionado con la defensa del Estado se permite por una buena razón [de Estado], en la misma medida que la guerra no debe ser por razones religiosas o de pureza de la fe».

\section{RAZÓN DE Estado}

Ludovico Settala diferencia la razón de Estado de la política en que esta «tiene como objetivo principal el bien público, mientras que aquella procura preferentemente el bien de los jefes de la república» (1988: I, i). Es lo que el Arzobispo de El rey más perfecto llama la «buena» razón de Estado, frente al maquiavelismo de Don Álvaro:

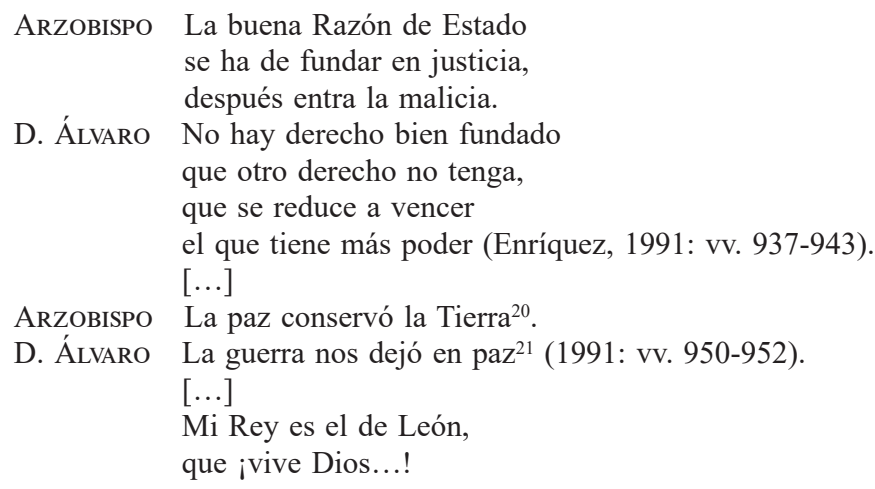

${ }_{19}$ Compárese con las alianzas del Papa con Venecia y Francia, y luego con Enrique VIII de Inglaterra, contra los imperiales en Las tres coronaciones de Carlos V; pues hay que separar el Derecho Civil de la Religión y esta subordinarla a aquel, como demuestran con los hechos las alianzas de Estados cristianos con turcos y paganos, como proponen Maquiavelo y Espinosa y como hace el Duque de Alba en esta comedia.

${ }^{20}$ «Lejos de la discordia de las armas, la misma tierra derrama por el suelo, con toda justicia, fácil alimento» (Virgilio, Geórgicas II, 459-460); Espinosa (2012: XVI, 3 en nota y 1986: III, 6 y 13).

${ }^{21}$ Según la máxima de Vegecio: «qui desiderat pacem, praeparet bellum» (Epitoma rei militaris III, Prefacio). En la Segunda parte de Enrique IV, de Shakespeare, es el Arzobispo de York quien defiende la guerra «no para romper la paz, sino para establecer una paz verdadera» (1991b: 543). En este sentido, dice Hobbes: «a consecuencia de la condición de guerra de cada hombre contra cada hombre, todos deben procurar la paz hasta donde tengan esperanza de lograrla»; «no repugna hacer de la paz el criterio para descubrir lo que es verdadero», pues «una nueva verdad jamás puede quebrantar la paz, sino sólo, a veces, reavivar la guerra; pues esos hombres que se atreven a tomar las armas para defender o introducir una idea, de hecho estaban ya en guerra» (2004: 120 y 164). 
ArzobISPo Más nobleza

fuera (sí, no os alteréis)

que donde tenéis los pies

tuviérades la cabeza (1991: vv. 956-960) ${ }^{22}$.

El maquiavelismo o doctrina de la razón de Estado concibe a este como un artificio destinado a afirmar y ampliar el poder. Hobbes lo formula diciendo que la ley tiene que ver con la autoridad, no con la verdad. El nuevo Leviatán o Magnus homo platónico (la persona representativa y soberana del Rey), que simboliza al Estado en la portada del tratado de Hobbes, es ahora fruto de un contrato entre individuos que ya «no afecta, como en las representaciones medievales, a una comunidad creada por Dios y a un orden natural preexistente, sino que es resultado de la razón y genio creador humanos» (Schmitt, 2004: 27). Por tanto, deja de tener sentido el derecho de resistencia, pues sería contradictorio construir un Estado para destruirlo después ${ }^{23}$.

Por el contrario, el racionalismo de la tradición aristotélico-tomista, a la que se adhieren los antimaquiavelistas, subordina el mandato personal del soberano (su poder) a la ley o ratio universal, ya que concibe como ideal del Estado la práctica de un ethos moral y jurídico, a través de la aplicación de dicha ley ${ }^{24}$. Concretamente para los antimaquiavelistas católicos, como el Arzobispo de El rey más perfecto o Calderón de la Barca, en A Dios por razón de Estado, la búsqueda de los principios que han de regir el Estado es un esfuerzo complementario de la razón natural y la revelación; pero cuando estas no nos basten, es sólo a la Iglesia a quien cumplirá orientar dicha búsqueda.

En relación con la disyuntiva anterior, las comedias políticas de Enríquez Gómez plantean siempre un conflicto entre los intereses del Estado (identificado con la persona del Rey) y del individuo ${ }^{25}$. Así, el Gran Can o primer minis-

22 Compárese con Platón (1988: 282-283); Maimónides (1994: I, 72) (quien achaca a las funciones físicas del cuerpo, carentes de reflexión y discernimiento, nuestras enfermedades y desdichas) y III, 17 («la Providencia está íntimamente ligada a la inteligencia»). Asimismo, Espinosa no dirige su Tratado teológico-político a la «multitud», porque sabe que sólo desea ser sierva, sino a quienes pueden transformar la imaginación y supersticiones de ella para mantenerla unida a la autoridad por obra de la obediencia. «Pues no es la obediencia, sino el fin de la acción lo que hace a uno esclavo» (2012: XVI, 3).

${ }^{23}$ Para Lope de Vega (Fuenteovejuna) y Calderón de la Barca (El alcalde de Zalamea), en cambio, la autoridad política sigue dependiendo de la autoridad religiosa y moral; de ahí el derecho de resistencia al tirano, que apela a la «justicia divina» mediante el leit-motiv del honor.

${ }^{24}$ Es el debate que sostienen Filo y Lelio en el tercer libro de la República, de Cicerón (1984). Sin embargo, para Jean Bodin el soberano es, como hemos visto, quien decide sobre la excepción a la ley; es decir, quien dispone de un poder que está por encima de ella.

${ }^{25}$ Tema que también plantean Hobbes, Espinosa y Montesquieu. Una de las doctrinas sediciosas que tienden a la disolución del Estado es la de que cada particular pretenda ser juez de las buenas y malas acciones o bien pretenda anteponer su conciencia a la ley civil, 
tro de Fernán Méndez Pinto aconseja el matrimonio de la princesa Pantalisa con el Rey de Tartaria, en contra de la voluntad de ella, a fin de evitar la guerra; pero luego descubrimos que el Gran Can pretendía suplantar en el trono al Rey de la China, y Méndez Pinto tiene que restablecer el orden.

En El maestro de Alejandro, Filipo quiere casar a su hijo con Julia, princesa de Egipto, aunque él desea a Octavia. Esta, sin embargo, aconseja a Alejandro que obedezca para no alterar la unidad del reino, aunque añade que ella se matará para no verlo «asistir en otro nido». «El Rey no ha de permitir / alterar el gusto mío» — replica Alejandro-, «que la suprema grandeza / no se opone al albedrío» (Enríquez, 1666: f. 179vb). Pero Octavia proclama:

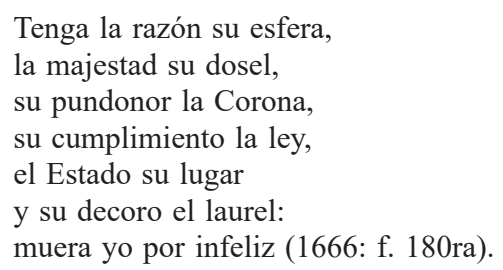

Como la princesa Julia está al corriente de la relación que mantienen Alejandro y Octavia, no quiere tomar estado «con esposo divertido»; hasta que Filipo zanja la cuestión decidiendo que Octavia se case con Camilo, infante de Sidón e hijo del Rey de Tiro; decisión política que aprueba Aristóteles si se ejecuta en «el tiempo más conveniente» y no precipitadamente,

\author{
porque hay tiempo en que no logra \\ la justicia por veloz, \\ por activa y rigurosa \\ el alma de la razón (1666: f. 181ra) ${ }^{26}$.
}

Al interpretar la simbología judeo-cristiana que subyace en el tratado político de Hobbes, Carl Schmitt sugiere que el Leviatán es, sucesivamente, un Dios mortal que sucumbió con las luchas religiosas y el Estado de Derecho ${ }^{27}$;

que es «la conciencia pública» a que debería atenerse (Hobbes, 2004: XXVIII); «si un hombre tuviera que hacer un día, por orden de la sociedad, algo que, a su juicio, contradijera la razón, ese perjuicio quedaría ampliamente compensado por el bien que surgiese del mismo Estado político; pues también es una ley de la razón que, de dos males, se elija el menor» (Espinosa, 1986: III, 6); «la virtud política es la renuncia de uno mismo y una preferencia continua del interés público sobre el interés de cada cual» (Montesquieu, 1985: I, iv, 5).

${ }_{26}$ Pues siendo el principio de la monarquía el honor, la administración de la justicia requiere investigaciones escrupulosas (Montesquieu, 1985: I, v, 10 y I, vi, 1).

${ }^{27}$ Cosa que los antimaquiavelistas como Pedro de Ribadeneyra reprochan a los sucesores del Anticristo florentino: «vienen a negar, si no con sus palabras, con sus consejos y 
una persona representativa y jurídica (el Rey o el Parlamento) y una máquina burocrática, contemporánea del positivismo jurídico (Schmitt, 2004: 9, 13 y 36). La base de la monarquía, en las comedias de Enríquez Gómez, aún fluctúa entre lo que Montesquieu llamará principio del honor ${ }^{28}$ y la construcción artificial, de naturaleza contractual, del Estado moderno.

En efecto, los títulos de estas comedias revelan la importancia que seguirá teniendo el concepto del honor en relación con el ejercicio del poder y la aplicación de la ley: A lo que obliga el honor y No hay contra el honor poder, de Enríquez Gómez, y Cuánto se estima el honor, de Guillén de Castro; comedia donde el Príncipe de Sicilia se lamenta de haber tenido que casarse por razón de Estado mientras acosa a la desdeñosa Celia, si bien termina salvando el honor de ambos cuando reconoce el derecho de Celia a casarse con Alejandro.

El planteamiento de la trama amorosa de No hay contra el honor poder es muy semejante: el príncipe Don Sancho, hijo de Alfonso X el Sabio, persigue a Doña Blanca, esposa de Don Rodrigo de Lara; pero ella lo rechaza desde el principio con tal entereza que hace entrar en razón a Don Sancho.

El conflicto planteado en $A$ lo que obliga el honor (Enríquez, 1642) tiene, por el contrario, un desenlace trágico. Doña Elvira lleva dos años galanteando con el príncipe Don Pedro, hijo de Alfonso XI; pero renuncia al amor del infante por no «alborotar la quietud del reino», aun sabiendo que «no hay mejor sepultura / para una mujer de ingenio / que un matrimonio forzado». Sin embargo, la loca pasión del Príncipe lo lleva a apostar «ser César o nada, que así / he de morir o vencer» y las palabras de Doña Elvira («arded, corazón, arded; / que yo no os puedo valer») no satisfacen a su futuro esposo, Don Henrique; quien no encuentra otra salida, para salvar el honor, que despeñarla durante una cacería, simulando un accidente ${ }^{29}$.

En El Gran Cardenal de España, dicho honor ha sido mancillado por la entrevista de Don Juan de Albornoz y Doña Ana en los aposentos reales (Enríquez, s. a.: Jornada Primera), y toca al hermano de aquel, Don Gil, juzgarlo y condenarlo al cadalso; pues siendo la razón de Estado «una noticia de los medios convenientes para fundar, conservar y engrandecer un señorío» (Botero,

vanas razones de Estado, que no hay Dios o que no tiene providencia de los Estados» (1597: 16).

${ }^{28}$ Montesquieu (1985: Advertencia del autor y I, iii,6). El declinar de la monarquía empezará cuando pierda este principio y los reyes, en lugar de ser sagrados, traten de demostrar que son aptos y útiles, compitiendo con personas y organizaciones que se revelarán tanto o más útiles que ellos; es decir, cuando la monarquía borbónica de la Restauración dé paso a la parlamentaria de un rey burgués, en julio de 1830 .

29 En la Castro, de António Ferreira y Reinar después de morir, de Luis Vélez de Guevara, la mujer amada por el príncipe Don Pedro también corresponde con su pasión a la de este y el final es igualmente trágico. En La venganza de Tamar, de Tirso, y Los cabellos de Absalón, de Calderón, en cambio, el objeto de deseo del Príncipe no corresponde a dicha pasión, lo que no evita que sea violada ni el desenlace igualmente trágico. 
1593: f. 1r) ${ }^{30}$, se deben evitar las «causas internas» por las que «caen los Estados», entre ellas, «la sensualidad de la carne que mancha la honra» (1593: f. $3 r$. $)^{31}$.

Durante su exilio, Gil de Albornoz se convierte en privado del Rey de Francia, a quien advierte de lo mismo: «es flaca naturaleza / abrazar lo racional / lo que el instinto no niega» ${ }^{32}$. Y Aristóteles, en El maestro de Alejandro, reprocha a los Músicos que los versos con que cantan los amores del príncipe Alejandro y Octavia, Duquesa de Utelino, «sean escritos / a la luz de la delicia» o de la naturaleza y no de la razón de Estado (Enríquez, 1666: f. 176ra). Idea que formula, poco después, mediante el aforismo

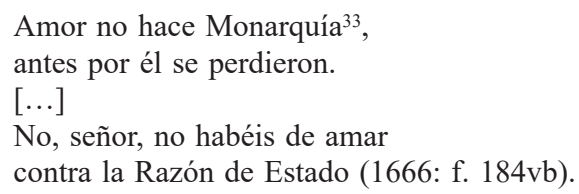

Después de lo cual, Alejandro parte a combatir a los persas para salvaguardar la reputación del reino (1666: f. 189rb) ${ }^{34}$.

Cuando Fernando III, el rey más perfecto, casa a Don Rodrigo con Doña Elvira, desagraviando así el honor del Conde de Orgaz, castiga al mismo tiempo a Don Rodrigo, pues «estuvo capitulado de casarse con mi hermana»-alega el Rey- y, por tanto, tiene que desagraviar el honor del monarca, que es también cuestión de Estado.

${ }^{30}$ Compárese con El rey más perfecto (1991: v. 1080) y El maestro de Alejandro: «el conquistar los imperios / más consiste en la fortuna / que en la fuerza; el mantenellos / en justicia es el blasón / imperial del vencimiento, / por ser mejor no ganallos / que ganallos y perdellos» (1666: f. 177va).

${ }^{31}$ El modelo mítico de derrumbe de un Estado por «las leyes del gusto» (Enríquez, s. a.: Acto Tercero) y la división interna es la «pérdida de España» por los amores del rey Rodrigo (Menéndez Pidal, 1924).

32 El Gran Cardenal de España, Don Gil de Albornoz. Segunda Parte. [manuscrito] (BNE Mss. 15.152 y 16.544), Jornada Primera.

33 «¿Cuál fue más poderosa en la elección de los reyes: la reputación o el amor? Sin duda fue la reputación, porque los pueblos no se movieron a ello por favorecer y complacer a nadie, sino por el bien público, y por esto no eligieron a los más graciosos y blandos, sino a los más valerosos» (Botero, 1593: f. 11v). La reputación y la conservación fueron conceptos clave en la Monarquía Hispánica, de los que se hace eco Enríquez Gómez aquí y en otros lugares (Calderón Calderón, 2016: nota 35).

${ }^{34}$ En el capítulo «De los Príncipes que por grandeza de reputación fueron llamados Magnos o Sabios», Botero destaca a Alfonso X (No hay contra el honor poder) y Fernando III (El rey más perfecto); este «porque fue el primero que juntó debajo de una corona los reinos de Castilla y de León, y porque con su gran valor ganó grandes estados de los moros, y no fue menos glorioso por justicia y religión que por arte de guerra y vitorias» (1593: f. 56v). 
La trama amorosa de Las tres coronaciones de Carlos $V$ remeda, con sus disfraces, las fidelidades y traiciones de la política ${ }^{35}$. Don Pedro de Silva ha abandonado a Doña Violante en Alemania y pretende casarse con Doña Inés en Bolonia. Elena, con mascarilla de hombre, entrega a Don Pedro un billete de desafío de un tal Don Diego de Bracamonte (en realidad, Doña Violante vestida de hombre), retándolo en el campo de «Bentiboli»,

porque si [Dios] vida me ha dado

y es una vida sin honra,

el perderla por la honra

es firme razón de Estado (Enríquez, 1675: f. 137va).

Pero hay algo más. María de Padilla reprocha a Gil de Albornoz, El Gran Cardenal de España, su sentencia fratricida:

Que muera don Juan es justo, mas que lo firme su hermano no lo apruebo: ¿qué tirano hiciera ese caso injusto?

Donde hay sangre no hay, señor, rigor (Enríquez, s. a.: Acto Segundo).

Tanto en este caso como en el siguiente, la relación patriarcal entre el Rey y sus súbditos está anclada en presupuestos iusnaturalistas. Fernando III lo pone de manifiesto una vez más cuando enfrenta la «razón de Estado» a la «ley de la naturaleza» (Enríquez, 1991: v. 870) ${ }^{36}$ :

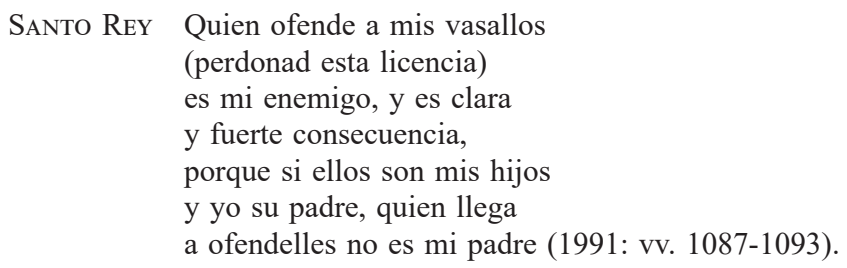

Al heredar Carlos V el Sacro Imperio de su abuelo Maximiliano, un Diputado de Castilla le pide también que no los abandone tan al principio de su reinado, estando aún sin sucesión, porque

35 «El mundo de la corte permite la galantería cuando va unida a los sentimientos del corazón o a la idea de conquista, y esta es la verdadera razón por la cual las costumbres no son nunca tan puras» (Montesquieu, 1985: I, iv, 2).

36 Según «el derecho natural de cada individuo, [...] nadie está obligado a vivir según el criterio de otro», pues «los súbditos retienen, por una especie de derecho de naturaleza, algunas cosas que no se les pueden quitar sin gran peligro para el Estado» (Espinosa, 2012: Prefacio, 3). 
primeros somos nosotros, que os amamos y servimos, que todos los imperiales.

A lo que el Emperador responde:

pero también son mis hijos quienes veneran mi nombre en reinos ultramarinos (1675: ff. 124vb -125ra).

Y justifica por «razón de Estado» la elección de dos extranjeros (Monsior de Gebres y su sobrino Guillermo de Croy) como «primer Ministro» y Arzobispo de Toledo, respectivamente, en contra de la opinión del Duque de Alba; quien alega, sin éxito, que «a la elección le faltaba / la aprobación natural».

\section{Justicia y Gobierno}

Una figura reiterada en estas comedias, por su vinculación con las tareas de Gobierno, es el privado o valido, que además suele dar nombre, directa o perifrásticamente, a la obra: Méndez Pinto, Gil de Albornoz, Demócrito y Aristóteles. Determinados apelativos del primero evocan, incluso, al Conde-duque de Olivares (Calderón Calderón, 2016: nota 28), como en la Segunda Parte de Fernán Méndez Pinto, donde el protagonista se convierte en «Alcides de este reino» $\mathrm{y}$ «Gobernador de sus estados», a quien el Rey de Tartaria llama «poderoso Atlante». Al ver que Fernando enseña a leer y escribir la lengua española al tosco Alcidamante, criado «entre fieras y peñascos», el Rey de Tartaria lo nombra virrey. Pero aunque es aficionado a la guerra, Alcidamante no sabe manejar las armas de fuego y un día quiere disparar a una paloma con tal mala suerte que al cargar la escopeta con demasiada posta, le revienta en la cara y queda moribundo ${ }^{37}$.

El protagonista de estas comedias es juzgado varias veces (Fernán Méndez Pinto) o ejerce de juez (El Gran Cardenal de España, El rey más pefecto). En el primer caso, la obra se desarrolla siguiendo el tópico de la rueda de la Fortuna, en sus tres fases: la exaltación del valido (en la Primera Parte, es guardián del Rey — «un pecado» común a todas las naciones, observa su criado Duarte-

37 Compárese con la «Carta del Conde-duque al Presidente de Castilla, 18 de septiembre de 1632», donde el valido de Felipe IV lamenta que «pocos hombres nobles tratan del estudio de las buenas letras que tanto ilustran y tan inexcusables son a toda profesión, del de las lenguas forasteras que tanto adornan, y que el ignorarlas deslustra tanto. [...] El jugar las armas, acción sin que paréceme no puede constar un hombre noble. [...] ¿Qué diré del salir a ver otras provincias para informarse de las costumbres naturales, forma de gobierno, fines del Estado intrínsecos y extrínsecos tan útiles?» (Elliott y De la Peña, 2013: 280). 
y virrey en la Segunda); la caída (en la Primera Parte es acusado de regicidio y en la Segunda, de traición de lesa majestad y asesinato) y la rehabilitación (en ambas partes se termina reconociendo su inocencia).

La causa de las tribulaciones de Méndez Pinto es siempre la enemiga de malsines o intrigantes como los cortesanos Tucapel, Pinol y Tiraín; cuyos equivalentes en otras comedias son Ricardo, Otavio, Hero y Lisipio, en Engañara para reinar; Tello, en No hay contra el honor poder, y el resentido y violento Don Pedro, en El Gran Cardenal de España. Como era convencional en la época, Antonio Enríquez Gómez hace depender las decisiones políticas del carácter y las pasiones de quienes las toman; pero la presencia de consejeros y validos que actúan guiados por el resentimiento ${ }^{38}$, la envidia ${ }^{39}$, la ambición egoísta y la hipocresía o el disimulo ${ }^{40}$ también pone en evidencia la responsabilidad del Rey y, por tanto, es una crítica a su autoridad.

Desde este punto de vista, el de la gestión del Gobierno, el protagonista de la Primera Parte de Fernán Méndez Pinto encarece al Rey de la China la variedad de Consejos con que se gobierna la Monarquía Hispánica (Enríquez, 1974: vv. 1695-1718); aunque, en realidad, existía una rivalidad entre Consejos y Juntas que solía extenderse a los niveles inferiores de la Administración y obstaculizaba el funcionamiento de la burocracia del Estado ${ }^{41}$.

Otras veces, los protagonistas de estas comedias expresan su opinión sobre el papel de determinados órganos jurisdiccionales y la forma de administrar justicia. En El rey más perfecto, Fernando III pone en evidencia la superior jurisdicción del Consejo Real, establecido como tribunal de casación frente a los tribunales venales de los distritos; pues esta «alma de los consejos» también se ha instituido por «razón de Estado» (Enríquez, 1991: vv. 1895-1897). Y en la tercera jornada de Fernán Méndez Pinto se levanta en el escenario un estrado con cinco escalones, una silla y un dosel para que la infanta Pantalisa, vestida de luto, presida sendos juicios contra el soborno a un ministro, el fraude de un abogado y el cohecho de un juez, que culminan con el del supuesto regicida Fernando. A cada lado de la infanta, se coloca un niño de pie: uno vestido de «morado» o «púrpura», con una espada («la justicia divina», Enrí-

38 Don Egas en El Duque de Viseo, de Lope de Vega, cuyas falsas acusaciones provocan el ajusticiamiento del protagonista.

39 De los cortesanos Íñigo y Ordoño, en Saber del mal y del bien, de Calderón; pero la demostración de la impostura no evita el destierro de don Pedro.

40 El cardenal Volseo, en La cisma de Ingalaterra, de Calderón.

41 Frente a los tradicionales Consejos, Olivares recurría a menudo a juntas especiales como la Junta Grande, creada en 1630 para hacer frente a los problemas de Italia. En 1634, creó la Junta de Ejecución para preparar la guerra contra Francia, que también actuó como gabinete de guerra durante la rebelión de Portugal. Estas Juntas estaban formadas por expertos de Guerra, Estado y Hacienda, muchos de los cuales no pertenecían a los Consejos, pero eran de la confianza del valido. 
quez, 1974: vv. 1975-1979) y otro vestido de blanco, con una palma («la misericordia», Enríquez, 1974: vv. 1970-1974) $)^{42}$.

De nuevo vemos asomar la realidad histórica a través de la ficción; entiéndase, en este caso, el sistema fiscal, financiero (arbitrios, servicios, sacas de metales, contrabando, fraudes, composiciones y retrocesiones) y político (jurisdicción especial, acceso a cargos municipales y oficios de justicia, refeudalización) de la Monarquía, basado en la explotación irracional de los recursos y en la corrupción sistémica: «legislar para componer», «un mal que la Monarquía consideraba menor ante el imperativo de su supervivencia» (Sanz Ayán, 2013: 111 y 333$)^{43}$. Las «dádivas y cohechos» habían sido, precisamente, «el polvo que cegaba a los jueces y la peste que consumía la república» en tiempos de Felipe III (Santa María, 1621: fol. 42v); síntomas, a su vez, de una corrupción e incuria generalizadas contra las cuales intentó reaccionar la generación de don Gaspar de Guzmán, aplicando las enseñanzas y orientaciones (que no reglas infalibles) de Tácito, a través de Justo Lipsio; ya que uno de los fundamentos para construir el Estado moderno, heredado de los antiguos romanos, era la justicia. Y el propósito de Olivares fue restaurar la que, a su juicio, regía en tiempos de Felipe II (Elliott y De la Peña, 2013: 40 y 44).

Enríquez Gómez critica, asimismo, la forma de designar a los mandos del ejército. «Elíjase General [...] / no por méritos de padres, / [...] que el don de sabiduría / no viene por línea recta» — añade Gil de Albornoz en la Segunda Parte $^{44}$. Aunque los blancos de sus críticas no son sólo representantes y funcionarios del Estado (ministros, generales, abogados y jueces); incluye también al Tercer Estado, representado por aquellos cuatro pícaros «de Torrejón de Velasco» que se enriquecieron en Méjico explotando la caridad ajena (Enríquez, 1974: vv. 2108-2167), y a la Iglesia. Cuando Fernando y Duarte llegan a Nanquín, se topan con un talagrepo o sacerdote de la región que guarda una ermita con tesoros.

DUARTE: Pues yo me fuera ermitaño desa suerte!

${ }^{42}$ Compárese con Proverbios 20:28; Séneca, De clementia. «La clemencia es la cualidad distintiva de los monarcas, pues siendo el principio de la monarquía el honor, todo lo que es motivo de vergüenza es un castigo» (Montesquieu, 1985: I, vi, 21). La fachada fingida de la iglesia de San Giacomo degli Spagnuoli, de Roma, durante los funerales de Felipe IV (1665), mostraba en su parte superior a la Clemencia y a la Justicia bajando del cielo con niños que portaban sus empresas (López Torrijos, 2006: 48).

${ }^{43}$ Compárese con los Memoriales y Cartas del Conde Duque de Olivares (Elliott y De la Peña, 2013: 333-334).

${ }^{44}$ El Gran Cardenal de España, Don Gil de Albornoz. Segunda Parte. [manuscrito] (BNE Mss. 15.152 y 16.544), Jornada Primera. Compárese con la sátira pseudoteatral El engaño en la vitoria de 1660 (Elia y Ocasar, 1996), donde se denuncia el nombramiento del General Luis Méndez de Haro por ser sobrino de Olivares y amigo de niñez de Felipe IV. 
TALAGRePO: No lo entiende;

pónenlo aquí para cambio,

que doy letras para el cielo

de todo lo que me han dado (1974: vv. 2222-2226).

Un tipo de justicia en la que hace hincapié Enríquez Gómez es la justicia distributiva. En la Primera Parte de El Gran Cardenal de España (Enríquez, s. a.: Tercera Jornada), este invita a reflexionar al Rey sobre ello,

\author{
pues siempre \\ cae la lluvia en las personas \\ más ricas y allí se queda, \\ porque son unas esponjas \\ de la república siempre \\ tan ingratas, tan odiosas, \\ que a los pobres les usurpan \\ lo que el cielo les otorga. \\ [...] \\ Alégranse los sembrados, \\ pues por mil abiertas bocas \\ pide que los alimente \\ la nube, que ya pregona \\ inundación de cristales, \\ fértil tesoro que goza. \\ Pero la nube soberbia, \\ que en las alas voladoras \\ de aire se juzga ingrata, \\ dellos se burla y arroja \\ sobre la mar los raudales. \\ $[\ldots]$ \\ Vos sois la nube y el sol \\ de Castilla poderosa; \\ mas cuando queréis llenar \\ de la lluvia milagrosa \\ a los vasallos, el cierzo \\ sale al paso y os estorba ${ }^{45}$.
}

45 «Sobre todas las otras cosas, en la Escritura es muy celebrada la misericordia de Dios [...] y él la encomienda mucho a los Príncipes, y no puede haber cosa más aparejada para ganar el amor del pueblo y obligarle al señor que esto. Los hebreos tienen por máxima que la limosna conserva las familias y las prospera en grandeza» (Botero, 1593: f. 28v). Compárese con la comedia Obrar bien en la privanza, de Manuel Coelho de Carvalho (1646), cuyo protagonista, «el privado para todos», funda la Misericordia de Lisboa con el patrocinio de Don Manuel I de Portugal, al tiempo que este es jurado como heredero de Castilla y Aragón. Cuando describe la Francia rural de mediados del siglo XIX, Karl Marx utiliza la misma imagen providencial y paternalista de la autoridad: «en la medida que no existe ninguna unión nacional y ninguna organización política, su representante tiene que aparecer como un señor, como una autoridad por encima de ellos, como un poder ilimitado de go- 
En la Segunda Parte, denuncia la ruina y los perjuicios que provocan las guerras en la población obligada a sostenerlas,

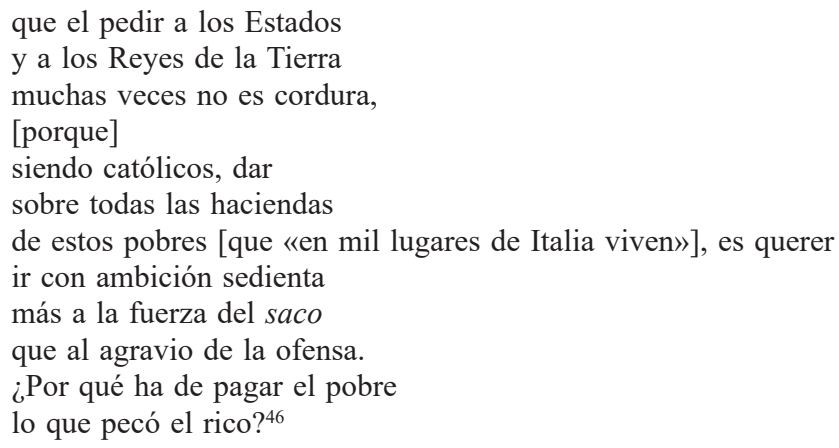

Mas al final, Don Gil de Albornoz es recibido por el Papa Inocencio como «gran restaurador de la silla de Roma», a quien «los malintencionados» reprochan que haya repartido la riqueza de la Iglesia entre los soldados, por lo cual «quejosa / está de vos la nobleza, / pero la plebe os adora / y los pobres, mucho más $\rangle^{47}$.

Respecto a la política fiscal, Fernando III razona así:

Don Rodrigo, no está el riesgo

en los tributos forzosos;

es que los vasallos buenos

contribuyan a su Rey.

En el disponer el medio

de sacar esos tributos

está el daño, y este ejemplo

califique mi doctrina:

Dios dijo al hombre primero

que contribuyese, y fue

admirable su precepto.

Para sacalle el tributo

de su lado, le dio sueño.

Sacó a Eva, pero fue

tan suavemente el feudo

que el hombre no lo sintió.

bierno que los proteja de las demás clases y les envíe desde lo alto la lluvia y el sol» (Marx, 1985: cap. 7).

${ }^{46}$ El Gran Cardenal de España, Don Gil de Albornoz. Segunda Parte. [manuscrito] (BNE Mss. 15.152 y 16.544), Jornada Primera.

47 Con ocasión de su vigésimo segundo cumpleaños, el príncipe Alejandro libera a los presos, da a los nobles «que son pobres» 3.000 ducados de ración y otros 30.000 a los «soldados que han servido» (El maestro de Alejandro, Jornada Segunda). 


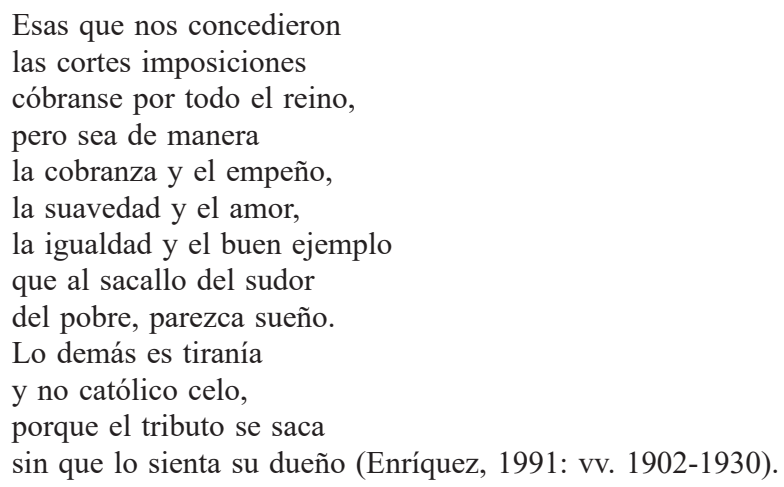

No obstante, para distribuir la riqueza no basta con evitar que se destruya en la guerra; es necesario producirla. Y para ello propone que «no entren fábricas jamás / en Castilla de otros reinos» (1991: vv. 1957-1958), las mismas «fábricas que vemos perdidas hoy» en el reino Castilla, a fin de «que en Castilla quede el dinero» y pueda invertirse para «que acaben los vagabundos» y se reactive la economía («alimentar el comercio») $)^{48}$.

A diferencia de Holanda e Inglaterra, afanadas en abrir mercados mediante las armas, la Monarquía Hispánica, con sus casticismos y prejuicios sobre el trabajo y el espíritu de empresa capitalista, se concentró en la defensa de la Fe. Si en lugar de exiliarse en la colbertista y mercantilista Rouan, Enríquez Gómez lo hubiera hecho en la Holanda de Jan de Witt, donde prevalecían la libertad de comercio y de religión, habría descubierto que esta última era el mejor medio para atraer y conservar capitales y mano de obra. En cambio, Fernando III exalta y apoya la fundación de una orden de predicadores y otra mendicante, ambas vinculadas a la Inquisición.

Este mismo rey reclama a su Consejo de Estado la universalidad de la justicia, reconociendo que

\author{
se distribuye \\ mal la justicia, pues vemos \\ que fue la soberanía \\ causa de infinitos yerros (1991: vv. 1853-1856).
}

Y para ilustrarlo repite una imagen empleada en la comedia anterior:

La nube del Rey no apruebo

que llueva sobre los ricos.

\footnotetext{
${ }^{48}$ El mejor modo de conservar la repúblicas es incentivar el comercio y el empleo, «procurando que en la ciudad aumenten las formas de ganar» (Settala, 1988: VII, xix).
} 
Despache al pobre primero, que sediento de favor, justicia le está pidiendo (1991: vv. 2131-2135).

El flamante Cardenal Don Gil de Albornoz, en la comedia del mismo título, tiene que resolver un pleito sobre el mayorazgo entre dos hermanos, mientras el Rey asiste al juicio detrás de una celosía.

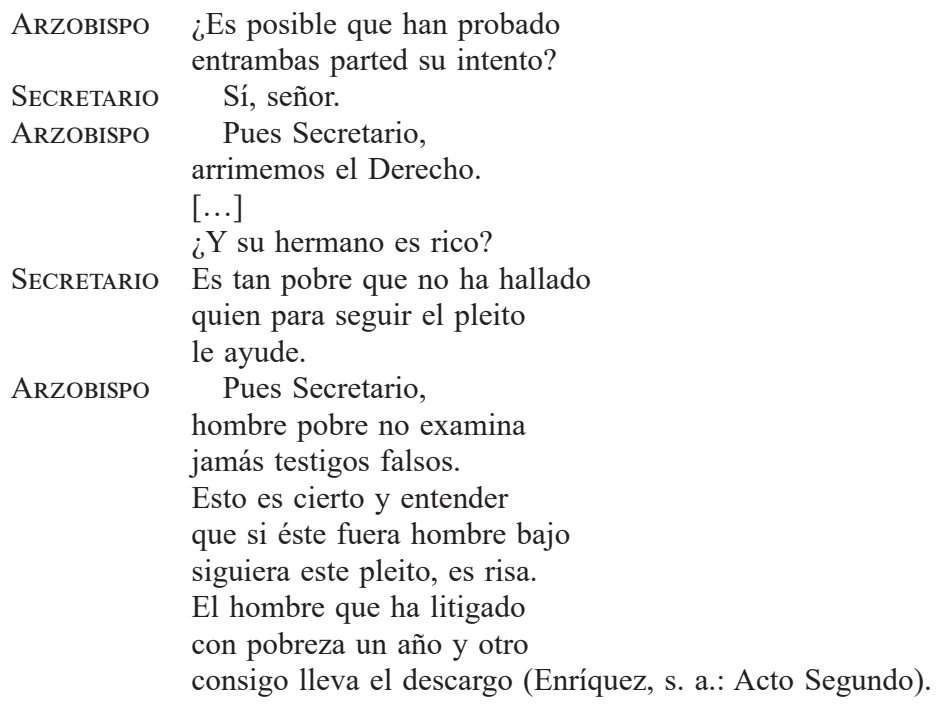

Otro tema relacionado con la justicia son los casos de honra (Calderón Calderón, 2016: nota 36), que aquí se imbrica con el motivo de los malsines o cizañeros. Después de caminar sin rumbo a campo traviesa, los fugitivos Fernán Méndez y Duarte llegan, de noche cerrada, a un palacio por una de cuyas puertas salen Pinol y Tiraín al tiempo que ellos entran por otra. Recorren a tientas su interior y en una habitación descubren el cadáver de una dama tendido en la cama. En ese momento, se cierra la puerta detrás de ellos y alguien les arroja un papel escrito, donde se explica esa muerte: Cayatel ha matado a su hermana porque había mancillado, con su liviandad y la de Tirendo, la honra familiar. Pinol aprovecha la ocasión para acusar a Fernando de haber querido violar a la hermana de Cayatel y como ella se resistiera, de matarla sin que él y Tiraín pudiesen impedirlo.

\section{PERDÓN y DEUS EX MACHINA}

Los emblemas o «jeroglíficos», a los que Enríquez Gómez suele recurrir para representar determinadas ideas en el escenario, forman parte del modelo 
doctrinal y estético del conceptismo y la varietas. Es el caso del león Barcino ${ }^{49}$ que, al comienzo de Fernán Méndez Pinto, rescata al héroe de una sima y le vuelve a salvar la vida al final de la Segunda Parte.

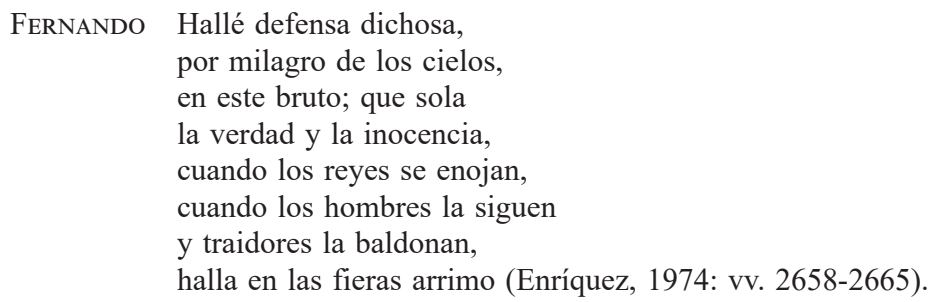

La Primera Parte había concluido con el intento de la infanta Pantalisa y Fernando de eliminar al Rey de Tartaria, disfrazados de naturales del reino; pero Fernando siente escrúpulos por tener que matar

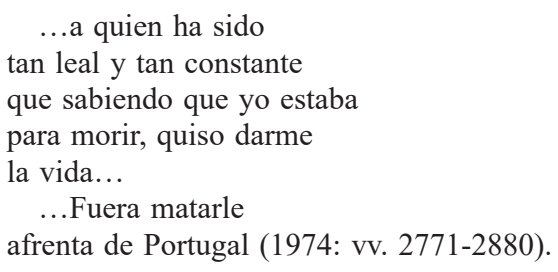

La reacción del rey tártaro sorprende a todos, postrándose ante el alfanje de Pantalisa; la cual, en vista de que él está dispuesto a morir por amor, le perdona la vida.

Hemos recordado, líneas más arriba, el fallo que el Cardenal Albornoz dio al pleito sobre la disputa de un mayorazgo. Don Pedro, uno de los pleiteantes, trata entonces de demostrar (porque «estaban benévolos los planetas / y en un nivel igualados») que la Naturaleza puede hacer iguales físicamente a dos hombres que no son hermanos. Ya al comienzo de la Primera Parte, Alonso el Bueno había dicho a su hijo en una carta: «en vos mi retrato asiste / y creo que tendrá España / un príncipe que la rija / con valor y con constancia». Y en la segunda jornada, el pleiteante Don Pedro usa un parecido pero «sofístico argumento», según el cual «esto se ve cada día: / nacer un hombre retrato / de otro mismo es un primor / que Naturaleza, al darlo, / copió la inventiva sola».

La respuesta del Arzobispo es una exposición escolástica sobre el hilemorfismo, irrelevante ante la fuerza y eficacia de un segundo objeto emblemático: el retrato del Rey, que salva la vida al juez por encontrarse en la trayectoria de

\footnotetext{
49 «Jeroglífico real / del valor, firme retrato / de la nobleza y piedad, / donde el Cielo ha dibujado / una luz de la justicia» (Enríquez, 1974: vv. 2397-2401).
} 
la bala que, con un anacronismo evidente, el frustrado Don Pedro le dispara. A partir de ahora, piensa Don Gil de Albornoz,

quien tiene tan fuerte amigo

ya no tiene qué temer:

ni la traición ni el poder

del más soberbio enemigo (Enríquez, s. a.: Acto Segundo).

Pues la virtud y legitimidad carismático-pneumática de la imagen o retrato del Rey equivale al poder y la legitimidad jurídica de su referente material:

Quien la vida me quitaba

muy poco a vos os temía,

que aunque delante os tenía,

poco o nada os respetaba (Enríquez, s. a.: Acto Segundo).

Convicción que comparte el Rey:

Ofender quiso a los dos

[y] más a mí me ofendió, que quien al retrato hirió, hiriera al original (Enríquez, s. a.: Acto Segundo).

Don Pedro había querido vengarse del juez acusándolo de prevaricación; pero al levantar falso testimonio, se hace merecedor del cadalso, en opinión del Rey. Aun así, este opta por la misericordia o clemencia (personificada, como vimos, en el emblema de la Primera Parte de Fernán Méndez Pinto).

Castigaros fuera error:

vos sois el mayor castigo de vos mismo y enemigo de todo humano favor (Enríquez, s. a.: Acto Segundo).

El rey más perfecto también perdona a Don Álvaro Núñez (condenado a la confiscación de sus bienes y a morir en prisión por haber alborotado el reino), pero por razón de Estado y en contra de la opinión del Arzobispo, ya que «hay que conservar los vasallos»y

los grandes de una corona, que son colunas del templo del Estado, no se arrancan (Enríquez, 1991: vv. 2230-2232) . $^{50}$

${ }^{50}$ «Una vez garantizada su seguridad en el tiempo futuro, un hombre debe perdonar las ofensas pasadas de aquellos que, arrepintiéndose de ellas, desean el perdón». Por otro lado, «la oferta de perdón hace que la perseverancia de los rebeldes sea ilegal» (Hobbes, 2004: 138 y 194). 
El «retrato» funciona, además, como speculum. Don Pedro el Cruel es el «retrato» de su padre Alfonso XI, a quien imita ejerciendo la misericordia y el perdón con Don Juan de Albornoz. Y en la Segunda Parte, el hermano de este, Don Gil, renuncia a ejecutar a Juan Vico, una vez más en contra de los deseos de la Iglesia —en este caso, del Papa-, porque ve en él un espejo de su propia condición humana;
que al paso que le di vida, le gané el pecho, y el modo
de ver si estaba leal
fue tratalle sin oprobio.
Es un cristal cualquier pecho,
y como está cauteloso
con la mancha del engaño,
al de Juan Vico y Astolfo
me miré yo muchas veces ${ }^{51}$.

En suma, las comedias de contenido político de Enríquez Gómez, aunque adolecen estéticamente de incoherencias ${ }^{52}$ y desaliños ${ }^{53}$, nos sirven para reflexionar sobre la realidad política de su tiempo; una realidad en trance de transformación, cada vez más alejada de una concepción teocrática o angélica de las relaciones de poder y más próxima a otra mecanicista, donde la autoridad no depende de la «verdad» y la «justicia» relativas a un orden (religioso, primero; natural después) anterior a la ley, sino de las normas derivadas de un contrato establecido entre los hombres.

Estas comedias presentan al vulgo como nueva realidad social que reclama un papel activo en la historia, si bien la autonomía que propuso Maquiavelo para la política, desvinculándola de la ética y la moral, seguirá dependiendo de las pasiones y la razón de los individuos, incluso en un antimaquiavélico como Hobbes, y no de la vida material colectiva, como propondrá mucho más tarde Karl Marx.

Por otra parte, aunque la base de la monarquía aún fluctúa, en estas comedias, entre lo que Montesquieu llamará el principio del honor y la naturaleza contractual del Estado moderno, la figura del gobernante soberbio personifica ya la prevalencia del poder sobre la ley.

${ }^{51}$ El Gran Cardenal de España, Don Gil de Albornoz. Segunda Parte. [manuscrito] (BNE Mss. 15.152 y 16.544), Jornada Tercera.

52 En la Segunda Parte de El Gran Cardenal de España, los criados Quiteria y Chinela han cambiado de amo, pues D. ${ }^{\text {a }}$ Ana y D. Juan de Albornoz han sido sustituidos por D. ${ }^{a}$ Leonor y D. Alonso; y en la tercera jornada, D. Diego, que no hace papel, es tío y hermano de D. ${ }^{a}$ Leonor. En Los dos filósofos de Grecia, Andrónico es llamado, al principio, Andonio.

${ }^{53}$ Los dos filósofos de Grecia acaba desmañada e inverosímilmente con el reconocimiento de Federico como Rey por parte de Lisipo y la boda de este con Niquea. 
Asimismo, la conducta de los protagonistas del teatro político de Antonio Enríquez Gómez ilustra la preponderancia de la acción (la fuerza y la voluntad) sobre el discurso o razón aristotélico-tomista, de acuerdo con la afirmación de Hobbes de que la ley tiene que ver con la autoridad y no con la verdad.

Por último, el sujeto de dicha autoridad es el Estado, encarnado por el Rey, quien debe (si no lo hace) garantizar la universalidad de la justicia. Y al Estado es a quien deben subordinarse, recíprocamente, los intereses y pasiones del individuo (razón de Estado).

\section{BIBLIOGRAFÍA CITADA}

Albiac, Gabriel (2013). La sinagoga vacía. Un estudio de las fuentes marranas del espinosismo. Madrid: Tecnos.

Aristóteles (1981). Ética a Nicómaco. Madrid: Centro de Estudios Constitucionales.

Aristóteles (1990). Retórica. Madrid: Gredos.

Aristóteles (1999). Política. Madrid: Gredos.

Bodin, Jean (1590). Los seis libros de la república de Juan Bodino, traducidos de lengua francesa y enmandados católicamente por Gaspar de Añastro Ysunza...Turín: herederos de Bevilaqua.

Botero, Giovanni (1593). Diez libros de la Razon de Estado. Con tres libros de las causas de la grandeza y magnificencia de las ciudades, traduzido de italiano en castellano por Antonio de Herrera. Madrid: Luys Sanchez.

Calderón Calderón, Manuel (2016). «Las comedias de Enríquez Gómez entre la Restauración portuguesa y la reformación de la Monarquía Hispánica», en Jacopo Masi, José Pedro Serra y Sofia Frade (dir.), Théâtre: esthétique et pouvoir. De l'antiquité cassique au XIXe siècle. Paris: Éditions Le Manuscrit, vol. I, pp. 101-123

Carvalho, Manuel Coelho de (1646). Obrar bien en la privanza y el privado para todos. Biblioteca Geral da Universidade de Coimbra, Ms. 582. Disponible en: <http://www. cet-e-seiscentos.com/> [ref. de 6/3/2017].

Cicerón (1984). Sobre la república. Madrid: Gredos.

Elia, Paola y José Luis Ocasar (ed.) (1996). El engaño en la vitoria. Sátira política en el siglo XVII. Madrid: Actas.

Elliott, J. H. y J. F. de la Peña (ed.) (2013). Memoriales y cartas del Conde Duque de Olivares. Política interior: 1621-1645, vol. I. Madrid: Centro de Estudios Europa Hispánica / Marcial Pons.

Enríquez Gómez, Antonio (s. a.). El Gran Cardenal de España, Don Gil de Albornoz [Primera Parte]. S. 1.: s. n.

Enríquez Gómez, Antonio (1642). A lo que obliga el honor, en Academias morales de las musas. Bourdeaux: Pedro de la Court, pp. 75-114.

Enríquez Gómez, Antonio (1645). Luis dado a Dios y Ana, Samuel dado de Dios a Elcana y Ana. París: René Baudry.

Enríquez Gómez, Antonio (1647). Política angélica. Roan [Rouen]: L. Maury.

Enríquez Gómez, Antonio (1663). Los dos filósofos de Grecia, en Parte diez y nueve de comedias nuevas y escogidas de los mejores ingenios de España. Madrid: Pablo de Val, a costa de Domingo Palacio y Villegas, h. 115v-137. 
Enríquez Gómez, Antonio (1666). El maestro de Alejandro, en Parte veinte y quatro de comedias nueuas y escogidas de los mejores ingenios de España. Madrid: Mateo Fernández de Espinosa Arteaga, a costa de Iuan de San Vicente.

Enríquez Gómez, Antonio (1675). Las tres coronaciones de Carlos V, en Parte quarenta de comedias nuevas de diversos autores. Madrid: Julián de Paredes, h. 118v-139r.

Enríquez Gómez, Antonio (1974). Fernán Méndez Pinto (Primera y Segunda Partes). Louise G. Cohen, Francis M. Rogers y Constance H. Rose (ed.). Cambridge (Massachusetts): Harvard University Press.

Enríquez Gómez, Antonio (1991). El Rey más perfecto. The Perfect King. Michael McGaha (intr., ed. y trad.). Tempe, Arizona: Bilingual Press.

Espinosa, Baruch (1977). Ética demostrada según el orden geométrico. Méjico: Fondo de Cultura Económica.

Espinosa, Baruch (1986). Tratado político. Madrid: Alianza.

Espinosa, Baruch (2012). Tratado teológico-político. Madrid: Alianza.

Gracián, Baltasar (1993). «El discreto», en Baltasar Gracián, Obras Completas II. Madrid: Turner.

Hobbes, Thomas (2004). Leviatán. Madrid: Alianza.

Hobbes, Thomas (2013). Diálogo entre un filósofo y un jurista, y escritos autobiográficos. Madrid: Tecnos.

López Torrijos, Rosa (2006). «La iconografía de la justicia en la época de Velázquez», en José Manuel Pita Andrade y Ángel Rodríguez Rebollo (coord.), Tras el centenario de Felipe IV. Jornadas de Iconografia y Coleccionismo dedicadas al profesor Alfonso E. Pérez Sánchez. Alcalá de Hernares: Universidad, pp. 39-58.

Luciano (1981). «El sueño o El Gallo», en Luciano, Obras I. Madrid: Gredos, pp. 362-392

Maimónides (Mošé ben Maimon) (1994). Guía de perplejos. Madrid: Trotta.

Maquiavelo, Nicolás (1991). El príncipe. Madrid: Tecnos.

Maquiavelo, Nicolás (2008). Discurso sobre la primera Década de Tito Livio. Madrid: Alianza.

Marx, Karl (1985). El 18 Brumario de Luis Bonaparte. Madrid: Sarpe.

Menéndez Pidal, Ramón (1924). «El rey Rodrigo en la literatura», Boletín de la Real Academia Española. XI, 52-55, pp. 157-197, 251-286, 349-387, 519-585.

Montesquieu, Charles-Louis de Secondat, barón de (1985). Del espíritu de las leyes. Madrid: Tecnos.

Platón (1988). «República», en Platón, Diálogos. Madrid: Gredos, vol. IV.

Révah, Israel Salvatore (2003). Antonio Enríquez Gómez, un écrivain marrane. París: Chandeigne.

Ribadeneyra, Pedro de (1597). Tratado de la religión y virtudes que debe tener el príncipe cristiano para gobernar y conservar sus estados. Contra lo que Nicolás Machiavelo y los Políticos deste tiempo enseñan. Amberes: Emprenta Plantiniana.

Santa María, Fray Juan de (1621). República y policía cristiana, Lisboa: Antonio Álvarez. Sanz Ayán, Carmen (2013). Los banqueros y la crisis de la Monarquía Hispánica de 1640. Madrid: Marcial Pons.

Schmitt, Carl (2004). El leviathan en la teoría del Estado de Thomas Hobbes. Granada: Comares.

Schmitt, Carl (2008). Los fundamentos histórico-espirituales del parlamentarismo en su situación actual. Madrid: Tecnos.

Schmitt, Carl (2009). Teología política. Madrid: Trotta.

Settala, Ludovico (1988). La razón de Estado. Méjico: Fondo de Cultura Económica. 
Shakespeare, William (1991a). «La primera parte de Enrique IV», en William Shakespeare, Obras Completas I. Méjico: Aguilar, pp. 449-504.

Shakespeare, William (1991b). «La segunda parte de Enrique IV», en William Shakespeare, Obras Completas I. Méjico: Aguilar, pp. 507-567.

Shakespeare, William (1991c). «Hamlet, príncipe de Dinamarca», en William Shakespeare, Obras Completas II. Méjico: Aguilar, pp. 219-289.

Shaw, George Bernard (1979). «Santa Juana», en George Bernard Shaw, Comedias escogidas. Madrid: Aguilar.

Fecha de recepción: 6 de diciembre de 2014 .

Fecha de aceptación: 26 de junio de 2015. 